\title{
Concurrent use of Antiretroviral and African traditional medicines amongst people living with HIV/AIDS (PLWA) in the e'Thekwini Metropolitan area of KwaZulu Natal
}

\author{
Mncengeli Sibanda,Manimbulu Nlooto M, Panjasaram Naidoo
}

Discipline of Pharmaceutical Sciences, School of Health Sciences, University of KwaZulu Natal (Westville Campus), Private Bag X54001, Durban 4000. South Africa.

\begin{abstract}
Background: People living with HIV/AIDS (PLWA) often use African Traditional Medicines (ATM) either alone or in combination with Western medicines including Antiretrovirals (ARV).

Objective: To explore the prevalence of concurrent Antiretrovirals (ARV) and African Traditional medicines (ATM) use and determine the effects of any concurrent use on the CD4+ Lymphocyte count and Viral Load (VL) of PLWA in the eThekwini Metropolitan area.

Methods: A descriptive and exploratory study was carried out on 360 patients. Information was gathered on patients socioeconomic characteristics, ATM usage, outcome measures of HIV disease progression (CD4+ Count, VL). The data was analysed using descriptive statistics, univariate and multivariate analyses.

Results: 4.98\% (14/281) of the patients used ATM and ARV concurrently during the study period. Over 65\% (185/281) reported ATM use before diagnosis with HIV whilst 77.6\% (218/281) reported previous ATM use after their HIV diagnosis but before initiation with ARV. Place of residence $(\mathrm{p}=0.004)$, age $(\mathrm{p}<0.001)$ and education level $(\mathrm{P}=0.041)$ were found to be significantly and positively correlated with ATM use. There were no statistically significant changes in mean plasma CD4+ Count and inconclusive effects on VL during the period of the study in the group taking ARV alone when compared with the group using ARV and ATM concomitantly.

Conclusion: Concurrent ARV and ATM use is quite low (4.98\%) when compared to ATM use before HIV diagnosis and after HIV diagnosis but before initiation with ARV. This may point to efficient pre-counselling efforts before ARV initiation by health care professionals. This study also demonstrated that there were no significant differences in the CD4+ and inconclusive effects on VL, between patients taking both ARV and ATM concomitantly and those using ARV alone.

Keywords: African traditional medicines, AIDS; ARV; complimentary medicines, Drug-Herb interactions, Herbal medicine,HIV; Indigenous medicine, Medical Pluralism, South Africa.
\end{abstract}

DOI: http://dx.doi.org/10.4314/ahs.v16i4.30

Cite as: Mncengeli S, Panjasaram N, Manimbulu N. Concurrent use of Antiretroviral and African traditional medicines amongst people living with HIV/AIDS (PLWA) in the eThekwini Metropolitan area of KwaZulu Natal. Afri Health Sci.2016;16(4): 1118-1130. http:/ / dx.doi. org/10.4314/abs.v16i4.30

\section{Introduction}

Human immunodeficiency Virus and Acquired Immune deficiency Syndrome (HIV/AIDS) has grown to pandemic proportions and has become a major health
Corresponding author:
Mncengeli Sibanda,
Discipline of Pharmaceutical Sciences,
School of Health Sciences,
University of KwaZulu Natal (Westville Campus),
Private Bag X54001, Durban 4000. South Africa
Tel: 012 3435829,
Cell: 0725877246
Email: mncengelis@gmail.com

problem Worldwide. Approximately 36.9 million people Worldwide are living with HIV and since 2000 around 25.3 million people have died as a result of AIDS related illnesses ${ }^{1}$. According to the 2014 Joint United Nations Programme on HIV and AIDS (UNAIDS ) update, sixtynine percent of people infected with the HIV live in SubSaharan Africa ${ }^{1}$. South Africa has an estimated 6.8 million people living with HIV and this represents the largest number of people living with HIV in any countryMS4 ${ }^{1}$. HIV/AIDS has worsened the demands on the health care system in Africa and has put an already overburdened system under further strain ${ }^{1}$. Antiretroviral therapy (ART) using antiretroviral drugs(ARV) is the only proven managementMS5 of HIV-infection and has led to reduction in HIV related opportunistic infections and AIDS related 
deaths, and have thus improved substantially the quality of life in People living with HIV/AIDS (PLWA) ${ }^{2}$.

It is estimated that there are approximately 200,000 African traditional healers in South Africa and that between 70 and 80 per cent of South Africans use the services of Traditional Health Practitioners (THP) ${ }^{3}$. South Africa like many developing countries has a pluralistic healthcare system wherein a modernised first world medical system co-exists with a variety of non-conventional health care systems such as local indigenous systems founded on traditional beliefs and practices ${ }^{4}$.

In South Africa, the use of modern medicines has never fully replaced the indigenous system, and THPs continue to be consulted by the black population including PLWA for a variety of reasons ${ }^{3}$. The commonly treated illnesses including nausea and vomiting, lack of energy, lack of appetite, skin disorders, weight loss and diarrhea. Traditional Medicine (TM) is also used to treat the side effects of ARV drugs as well as fungal infections, dizziness, stomach upsets and pain5. Other reasons for TM use in PLWA is to supplement dietary intake, boost energy levels and improve immune response as well as a misguided belief that some TM can cure HIV/AIDS6. African traditional medicines (ATM) are regarded as a credible and convenient source of health care and dual treatment regularly takes place as a result ${ }^{4}$. THP thus have a crucial role to play in building the health system of South Africa including the management of PLWA ${ }^{5}$.

During the peak of the HIV/AIDS pandemic in the late 1990's before the era of massive ARV roll-out programs, when ARVs were largely unaffordable and inaccessible, ATM were the mainstay of HIV management amongst PLWA in Africa ${ }^{5}$. The advent of ARV rollout programs did not substitute ATM use amongst the population ${ }^{3}$ and many studies attest to this. In Uganda for example, a 2007 study showed that $63.5 \%$ of PLWA had used TM after HIV diagnosis and same-day, concomitant ATM and ARV use was reported by $32.8 \%$ of the patients surveyed $^{7}$. In a tertiary hospital in Kano, NorthWest Nigeria, it was found that $4.25 \%$ of the 430 patients surveyed used ARV and traditional medicine concomitantly ${ }^{8}$. A survey of 67 PLWA done at three ART centres in the Kumasi Metropolis in Ghana found that concomitant TM and ARV use was reported by $53.2 \%$ of the patients 9 An astounding $98.2 \%$ of 388 patients interviewed at the Family Care Centre (FCC) ART clinic in Harare, Zimba- bwe were found to be using at least one ATM concurrently with their ARV medication ${ }^{10}$.

A cross-sectional survey done in 2007 among PLWA attending a workplace ART clinic in South Africa found that $23 \%$ used ATM concurrently with their ATM ${ }^{6}$. A 2012 cross-sectional study which involved 100 participants enrolled at ARV clinics in two South African provinces showed that less than $20 \%$ of participants used TM and ARV simultaneously ${ }^{11}$. However, close to $80 \%$ of participants utilised TM before contracting HIV, which is in keeping with approximate estimates by the $\mathrm{WHO}^{12}$. According to Malangu, 7.7\% PLWA on ART in Pretoria, South Africa, concurrently used traditional health, care and over-the-counter medicines ${ }^{13}$.

Although the use of Traditional Medicines (TM) is widespread, their use is not well researched, and consequently poorly regulated ${ }^{4}$. Limited meta-analyses of safety and efficacy exist and low-level evidence of harm identifies the potential for herb-drug interactions (HDI) with many medicines including the commonly used ARV ${ }^{14}$.

The potential HDI may occur in similar fashion to the typical Drug-Drug interactions (DDI) at any of the stages of absorption, distribution, metabolism and excretion (ADME) phases of the pharmaceutical disposition of the drug in the human body affecting the entire pharmacokinetic profile of the $\mathrm{drug}^{15}$. Herb-induced inhibition or induction of the cytochrome enzymes can alter the metabolism of ARVs, leading to adverse effects or lack of efficacy15.The concomitant intake of TM in patients using ARVs may result in lowering of plasma drug concentrations resulting in treatment failure, drug resistance and possibly death of the patient ${ }^{15}$. Alternatively, concomitant intake may also result in increased plasma drug concentrations resulting in drug toxicity ${ }^{15}$.

Mills et al. in 2005 showed that extracts of African potato (Hypoxis hemerocallidea) had significant effects on cytochrome P450 3A4 in-vitro metabolism and so potentially could result in sub-therapeutic plasma concentrations ${ }^{16}$. A 2014 laboratory study of the inhibition of major drug metabolising enzymes by Hypoxis hemerocallidea(H. hemerocallidea), Echinacea purpurea (E. purpurea), Moringa oleifera (M. oleifera), Taraxacum officinale ( $T$. officinale) and Lessertia frutescens (L. frutescens) demonstrated that TM have the potential to interact with $\mathrm{ARV}^{17}$. Conversely, a 2013 study on adult volunteers, by 
Gwaza et al. showed that Hypoxiswhen taken concurrently with lopinavir/ritonavir(LPV/r)is well-tolerated and is not associated with clinically significant changes in $\mathrm{LPV} / \mathrm{r}$ pharmacokinetics ${ }^{18}$. International guidelines for the management of HIV/AIDS recommend the use of plasma viral load (VL) measurements as the key tool in predicting HIV viral suppression and treatment success for patients on $\mathrm{ART}^{19}$. In resource limited settings which have inadequate access for VL measurements, treatment outcomes in PLWA on ART are measured using other clinical tools such as CD4+ T-cell (CD4) count, changes in the patient's Body Mass Index (BMI) as well as the presence or absence of opportunistic diseases ${ }^{20}$. Notwithstanding the laboratory studies mentioned above and others, and the known,albeit usually sub-clinical DDI in the components of most ART regimens, there remains no definitive position by most policy makers on the effect of individual ATM on the effects of concurrent use of ART and ATM on VL and CD4+ counts amongst PLWA due to the absence of a large randomised control trials.

\section{Aim and objectives:}

Objective of the study was to explore the occurrence of concurrent ART and ATM use amongst PLWA in the eThekwini Metropolitan area with the following aims: to determine the socio-demographic profiles of the respondents, the types of ATM used and the reasons for their use of ATM with ARV as well as to determine the effects of any concurrent use on the CD4+ Lymphocyte count and Viral Load (VL) of such patients.

\section{Ethical considerations}

Ethical clearance for the study was obtained from University of KwaZulu-Natal Biomedical Research Ethics Committee (BREC REF: BE272/14), the KwaZulu-Natal health Research Committee (REF: HRKM240/14) in the provincial Department of Health as well as permission from the CEO's of the four health institutions before data collection commenced.

\section{Methods}

\section{Design, setting and study population}

The study was conducted in two phases. The first phase was a cross sectional descriptive study aimed at collecting information on patient demographics and ATM use as well as to recruit participants for the second phase of the study. The second phase was a longitudinal study which involved data collection from the patient's charts using a case report form. The study was carried out in the region of the eThekwini Metropolitan area. The eThekwini metro is a mostly urban area consisting of approximately 3.5 million people and is located in the east coast of the Republic of South Africa (RSA) ${ }^{21}$. The population is comprised mostly of black African $(73.8 \%)$, followed by Indian/Asian (16.7\%), White (6.6\%) and coloureds $(2.5 \%)^{21}$. The population is serviced with sixteen provincial hospitals and eight community health centres ${ }^{22}$. This study was conducted at four public health facilities that supply ARV treatment in the eThekwini Metropolitan (Metro) area. These facilities were randomly selected from a list supplied by the provincial department of health of facilities that supply ARV treatment in the metro. A minimum sample size of $360 \mathrm{HIV}$-infected, treatment experienced adults ( $\geq 18$ years old) was determined to be a suitable number in order to cater for any 'loss to follow up' patients. Every second patient attended to at the health facility was approached with the study information leaflet to participate in the study. After obtaining their consent ,patients were recruited continuously until the desired sample size of 360 participants who met the inclusion criteria was achieved. Only patients who had been stabilised on the same fixed dose first-line ART regimen which consists of tenofovir (TDF), emtricibatine (FTC) and efavirenz (EFV) for the past 6 months were considered for the study. Patientsof the FDC were preferred by the researcher as this is the most commonly used first line regimen according to current treatment guidelines ${ }^{23}$. Furthermore, patients on the FDC were deemed to be more likely to be compliant to treatment and so negate non-adherence as a confounder to treatment failure ${ }^{23}$.

\section{Instrument, data collection, capture and analysis}

An anonymous coded questionnaire was administered to each of the selected 360 participants. The variables gathered included characteristics such as age, gender,ethnicity, level of education and place of residence. Other variables collected include current ARV regimen, previous and current ATM use, names and routes of administration of ATM used, reason for ATM use and awareness of any dangers in concurrent ATM and ARV use. Based on responses from this phase, patients were divided into two cohorts; users of ARV alone (-ATM) or users of both ARV and ATM (+ATM). 
Subsequent to the collection of the above mentioned patient data, a second phase of the study was initiated. This was a longitudinal study which involved data collection of patient clinical information from the patient's charts using a Case Report Form (CRF). The data was collected both retrospectively (6 months) and prospectively (over 12 months, in six month intervals). Clinical data collected included CD4+ lymphocyte counts, patient Viral load (VL), treatment failure, presence of Adverse Drug Reactions (ADR) and Opportunistic infections (OI) as well as any documented ATM use if available.

The data was then captured and analysed using Statistical Package for the Social Sciences Package for Windows ${ }^{\circledR}$

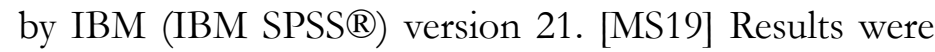
expressed in terms of frequency, mean values and Standard Deviations (SD). Frequencies and proportions (\%) were calculated to describe categorical variables such as age, gender, place of residence, level of education and ATM use. Results from open ended questions were captured using IBM SPSS ${ }^{\circledR}$. Categories were developed and responses were sorted and tabulated according to labelled categories to allow for sorting and counting of responses. Average CD4+ and VL for both cohorts at Time 0 (6 month retrospective), Time 1 (Baseline), Time 2 (6 month prospective) and Time 3 (12 month prospective) were determined. In the event of the patient charts having missing clinical information (one or more missing CD4+ and/or
VL measurements), the average[MS20] of the available readings would be used in the place of the missing data. The association between the Health outcomes (Average CD4+ counts and VL) and use of ATM were examined using a standard t-test for independent means. A statistician was consulted to verify the statistical analysis.

\section{Results}

\section{Excluded participants.}

Out of the subset of 360 patients who met the inclusion criteria and so chosen to participate in this study, 79 patients were excluded due to 'loss to follow-up' either through death (4 patients) or through completely unusable clinical information in the patient charts (absent CD4+ or VL).

\section{Socio-demographic characteristics}

Out of the remaining 281 patients surveyed, 69.9\% were females and almost all (96.8\%) were of African (black) ethnicity. The mean age of the participants was 39 (with a range from 19 to 69 years). The majority of the participants were relatively under-educated with only $6.7 \%$ having obtained a tertiary qualification and most (48.4) only having a primary education. It was also found that the majority of the patients $(64.4 \%)$ resided in an urban township.

The sample size population characteristics are depicted in figure 1 ;

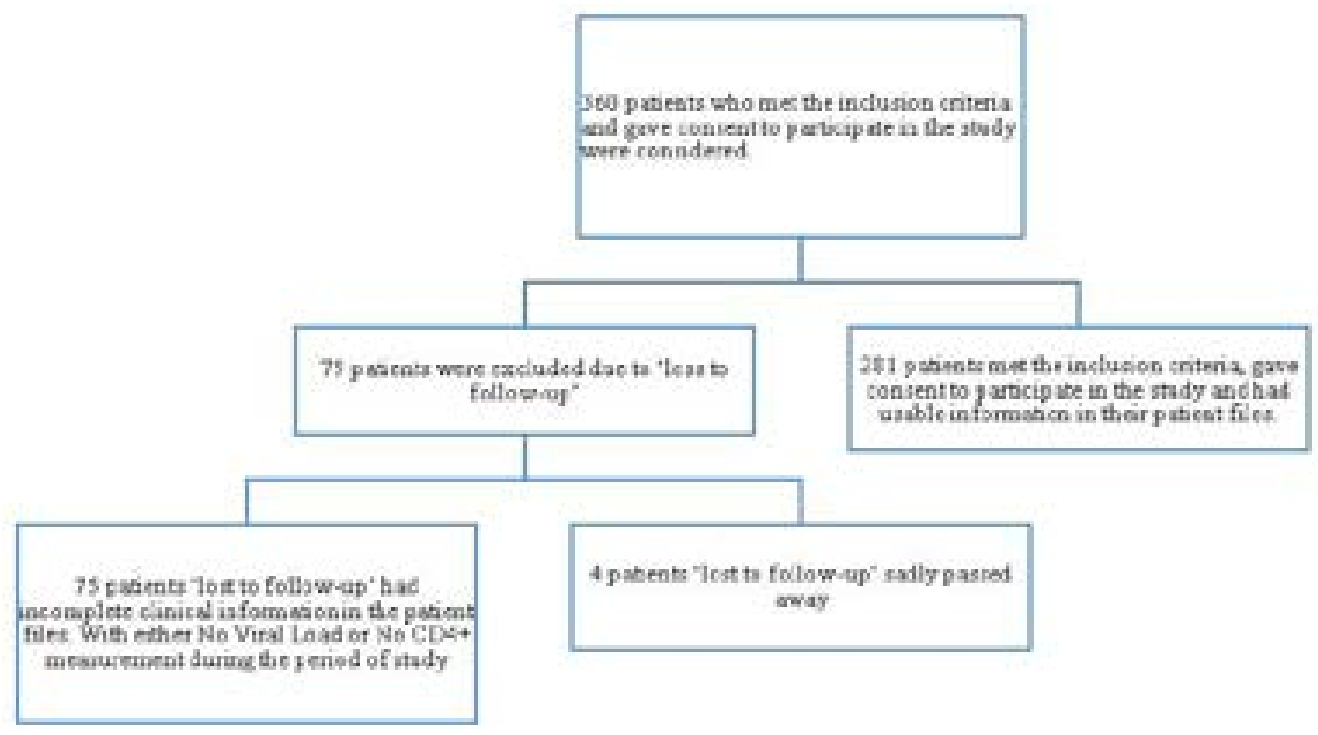

Figure 1: Sample Size Population Characteristics 


\section{Demographics and ATM use}

The majority (71.4\%) of concurrent ATM and ARV (+ATM) users were Africans (black) above the age of 40 and resided in urban townships (57.1\%). Most of the patients $(85.7 \%)$ who took ATM concurrently with ARV had primary education or lower qualification. Sixty three (22.4\%) patients reported to never have used ATM.

Table 1 shows summary demographic characteristics of patients surveyed, stratified by ARV users only or ARV and ATM users.

Table 1: Demographic characteristics of patients surveyed $(\mathrm{N}=\mathbf{2 8 1})$

\begin{tabular}{|c|c|c|c|}
\hline Patient Characteristic & $\begin{array}{l}\text { ARV users only } \\
(\%)\end{array}$ & $\begin{array}{l}\text { ARV and ATM } \\
\text { users }(\%)\end{array}$ & Total [n (\%)] \\
\hline \multicolumn{4}{|l|}{ Age } \\
\hline $18-25$ & 96.3 & 3.7 & $27(9.6)$ \\
\hline $25-35$ & 97.2 & 2.8 & $72(25.6)$ \\
\hline $30-35$ & 98.1 & 1.9 & $53(18.9)$ \\
\hline $40-45$ & 95.3 & 4.7 & $43(15.3)$ \\
\hline $45-50$ & 92.3 & 7.7 & $52(18.5)$ \\
\hline$>50$ & 88.2 & 11.8 & $34(12.1)$ \\
\hline \multicolumn{4}{|l|}{ Gender } \\
\hline Male & 90.8 & 9.2 & $87(30.1)$ \\
\hline Female & 96.9 & 3.1 & $194(69.9)$ \\
\hline \multicolumn{4}{|l|}{ Ethnic Group } \\
\hline Black & 94.9 & 5.1 & $272(96.8)$ \\
\hline White & 0 & 0 & 0 \\
\hline Indian & 100 & 0 & $3(1.1)$ \\
\hline Coloured & 100 & 0 & $6(2.1)$ \\
\hline Other & 0 & 0 & 0 \\
\hline \multicolumn{4}{|l|}{ Level of Education } \\
\hline No Education & 94.2 & 5.8 & $69(24.6)$ \\
\hline PrimaryEducation & 94.1 & 6.9 & $136(48.4)$ \\
\hline Secondary Education & 96.5 & 3.5 & $57(20.3)$ \\
\hline Tertiary Education & 100 & 0 & $19(6.7)$ \\
\hline \multicolumn{4}{|l|}{ Place of Residence } \\
\hline Urban Suburban & 98.3 & 1.7 & $58(20.6)$ \\
\hline Urban Township & 95.6 & 4.4 & $181(64.4)$ \\
\hline Peri-Urban & 90 & 10 & $30(10.7)$ \\
\hline Rural & 83.3 & 16.7 & $12(4.3)$ \\
\hline
\end{tabular}

14 out of the $281(4.98 \%)$ patients reported concurrent use of ATM with ARV(+ATM) during the study period. Of the total patients surveyed. 65.8\% reported ATM use before diagnosis with HIV whilst $77.6 \%$ reported previous ATM use after their HIVdiagnosis (but before initiation with ARV). This is shown in Fig. 2; 


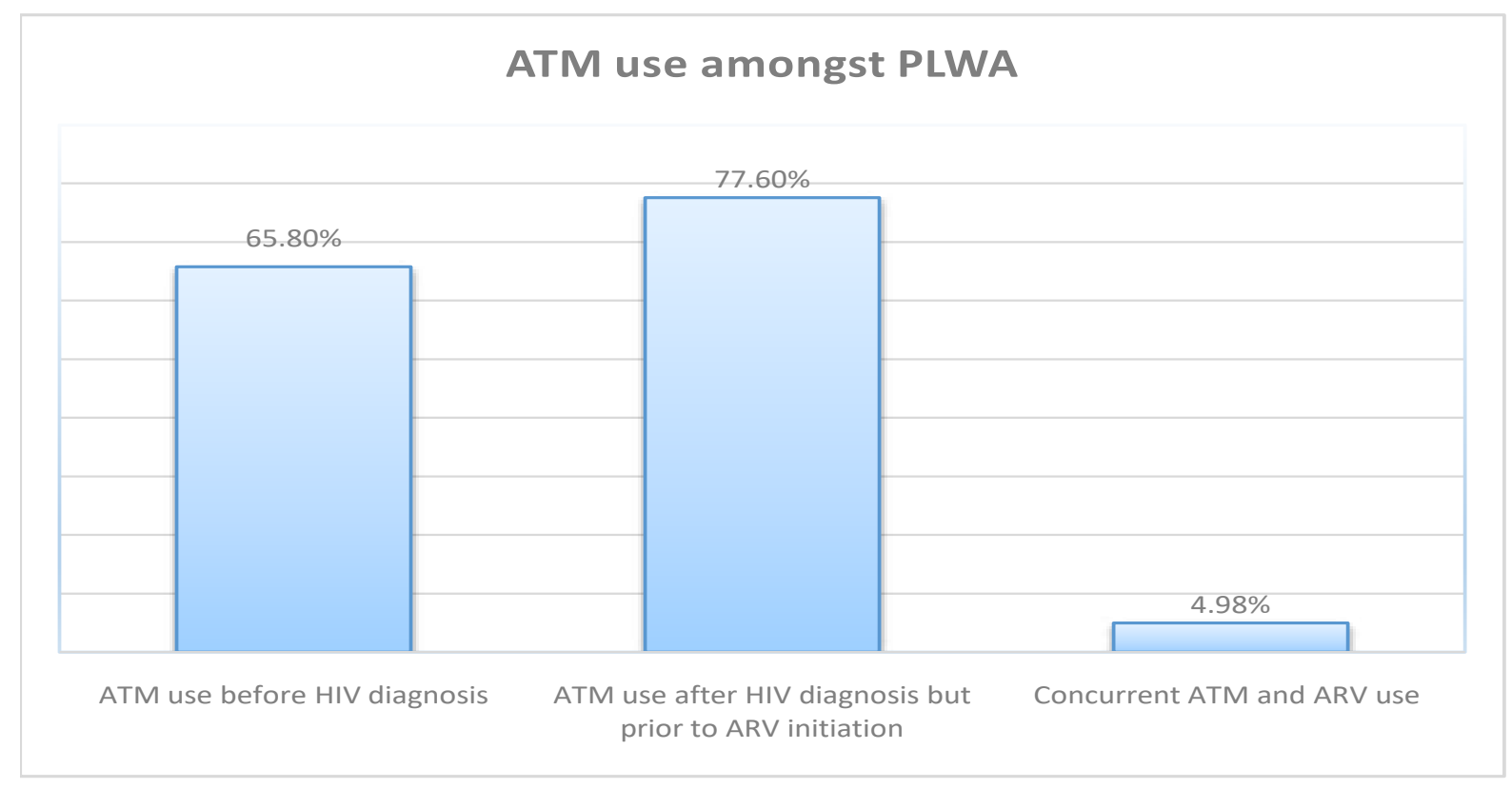

Figure 2: ATM use amongst PLWA

None of the patients in the +ATM cohort had a tertiary qualification and all were of African ethnicity. Univariate analysis for predicting ATM use was significantly as well as positively correlated with gender $(p<0.001)$, age $(\mathrm{p}=0.032)$ education level $(\mathrm{p}<0.001)$ as well as place of residence $(p=0.032)$. Multivariate analysis, obtained from combining all independent and controlling factors, for predicting ATM use resulted in education level $(\mathrm{p}<0.041)$, place of residence $(p=0.004)$ and age $(p<0.001)$.

Further details are elucidated in Table 2 
Table 2: Statistical association of independent variables to predict ATM use

\begin{tabular}{|c|c|c|c|}
\hline Patient Characteristic & $\begin{array}{l}\text { \% Concurrent ARV } \\
\text { and ATM use }\end{array}$ & $\begin{array}{l}\text { Univariate } \\
\text { value }\end{array}$ & p multivariate $p$ value \\
\hline \multicolumn{4}{|l|}{ Age } \\
\hline $18-25$ & 7.14 & 0.032 & $<0.001$ \\
\hline $25-35$ & 14.28 & & \\
\hline $30-35$ & 7.14 & & \\
\hline $40-45$ & 14.28 & & \\
\hline $45-50$ & 28.57 & & \\
\hline$>50$ & 28.57 & & \\
\hline \multicolumn{4}{|l|}{ Gender } \\
\hline Male & 57.14 & $<0.001$ & $<0.018$ \\
\hline Female & 42.86 & & \\
\hline \multicolumn{4}{|l|}{ Ethnic Group } \\
\hline Black & 100 & $<0.001$ & $<0.001$ \\
\hline \multicolumn{4}{|l|}{ Level of Education } \\
\hline No Education & 28.57 & $<0.001$ & $<0.041$ \\
\hline Primary Education & 57.14 & & \\
\hline Secondary Education & 14.29 & & \\
\hline \multicolumn{4}{|l|}{ Place of Residence } \\
\hline Urban Suburban & 7.14 & 0.032 & 0.004 \\
\hline Urban Township & 57.14 & & \\
\hline Peri-Urban & 21.43 & & \\
\hline Rural & 14.29 & & \\
\hline
\end{tabular}

\section{Types of ATM}

The most commonly used ATM amongst the +ATM group was the African potato (H. hemerocallidea); used in its crude form or commercial preparations such as Inkomfe capsules or Moducare $\left.{ }^{\circledR}\right)$ which was used by 9 patients $(64.3 \%)$. This was followed by Sutherlandia at $21.4 \%$. Two of the +ATM patients routinely used Stametta ${ }^{\mathrm{TM}}$ (a commercially prepared mixture of herbs including Aloe, aniseed oil and other nutrients which is sold Over-thecounter in pharmacies and health shops and is purported to 'strengthen the immune system and improve general well-being) and ubhejani (a traditional concoction of unknown composition sold in muthi markets in downtown Durban and townships). The average time for utilisation of ATM for the patients who took ARV and ATM con- currently was 4.3 months. In response to whether or not they had informed their medical doctor of their concurrent ATM use, all 14 patients $(100 \%)$ responded negatively and indicated that their doctors were not aware of their concurrent use of ATM.

\section{Reasons for ATM use}

$77.5(218 / 281)$ of the patients claimed to have previously or currently used ATM and cited one or more reasons for using ATM. Reasons for using ATM included to boost immunity $(68 \%)$, increasing appetite $(61 \%)$, tonic for fatigue $(55 \%)$, treating stomach pains/diarrhea $(27 \%)$, alleviating fever $(21 \%)$, treating joint pains $(13 \%)$, treating headaches $(11 \%)$, treating ARV side effects $(7 \%)$ and elevating mood (4\%). This is depicted in the table below 3; 
Table 3: Utilisation of ATM $(n=218)$

\begin{tabular}{|l|l|}
\hline Indication & $\begin{array}{l}\text { Percentage (\%) } \\
(\mathrm{n}=218)\end{array}$ \\
\hline Immune Supplementation & 68 \\
\hline Increasing Appetite & 61 \\
\hline Tonic & 55 \\
\hline Abdominal symptoms (Stomach pain/diarrhea) & 23 \\
\hline Fever & 21 \\
\hline Joint Pain & 13 \\
\hline Headache & 11 \\
\hline Treating ARV symptoms & 7 \\
\hline Elevating mood & 4 \\
\hline No particular reason & 2 \\
\hline
\end{tabular}

91\% (256/281) of the patients cited knowledge of the potential interactions between ATM and ARV and mentioned that the health care provider had underscored the potential dangers of simultaneous ARV and ATM use to them during pre-counselling before initiation of ART.

\section{Clinical information}

\section{Effect on CD4}

The majority $(72 \%)$ indicated living with HIV for at least
3 years. As per the inclusion criteria, all patients surveyed were on the FDC drug, or its singular components (Tenofovir + Emtricitabine/3TC + Efavirenz) for a minimum period of 6 months. Based on the commencement of current ARV regimen, it was found that average period of use of the FDC combination drug at the time of first contact with the patients was 9.3 months. Information on previous ARV regimens was scanty and so was excluded from the study. The mean CD4+ values for the study period are represented in Table 4;

Table 4: CD4+ counts

\begin{tabular}{|c|l|l|l|l|}
\hline & \multicolumn{2}{|c|}{-ATM $(\mathrm{n}=267)$} & \multicolumn{2}{|c|}{+ ATM+ (n=14) } \\
\cline { 2 - 5 } & $\begin{array}{l}\text { Mean CD4+ } \\
\text { (SD) }\end{array}$ & $\begin{array}{l}\text { Change from } \\
\text { baseline }\end{array}$ & $\begin{array}{l}\text { Mean CD4+ } \\
\text { (SD) }\end{array}$ & $\begin{array}{l}\text { Change from } \\
\text { baseline }\end{array}$ \\
\hline $\begin{array}{c}\text { Time 0, } \\
6 \text { months } \\
\text { Retrospective) }\end{array}$ & $\begin{array}{l}507 \quad( \pm 117.3) \\
\text { cells } / \mathrm{mm}^{3}\end{array}$ & $+1.2 \%$ & $\begin{array}{l}480 \quad( \pm 66.5) \\
\text { cells } / \mathrm{mm}^{3}\end{array}$ & $-0.6 \%$ \\
\hline $\begin{array}{c}\text { Time 1, } \\
\text { Baseline }\end{array}$ & $\begin{array}{l}501 \quad( \pm 128.3) \\
\text { cells } / \mathrm{mm}^{3}\end{array}$ & N/A & $\begin{array}{l}483 \quad( \pm 81.5) \\
\text { cells } / \mathrm{mm}^{3}\end{array}$ & N/A \\
\hline $\begin{array}{c}\text { Time 2, } \\
6 \text { months } \\
\text { Prospective) }\end{array}$ & $\begin{array}{l}519 \quad( \pm 141.0) \\
\text { cells } / \mathrm{mm}^{3}\end{array}$ & $+3.6 \%$ & $\begin{array}{l}512 \quad( \pm 59.7) \\
\text { cells } / \mathrm{mm}^{3}\end{array}$ & $+6.0 \%$ \\
\hline $\begin{array}{c}\text { Time 3, } \\
12 \text { months } \\
\text { (Prospective) }\end{array}$ & $\begin{array}{l}552 \quad( \pm 131.5) \\
\text { cells } / \mathrm{mm}^{3}\end{array}$ & $+9.2 \%$ & $\begin{array}{l}529 \quad( \pm 49.5) \\
\text { cells } / \mathrm{mm}^{3}\end{array}$ & $+9.5 \%$ \\
\hline
\end{tabular}


The mean baseline CD4+ count in the ATM cohort was 501 cells $/ \mathrm{mm}^{3}$. There was a $9.2 \%$ increase in CD4+ counts in the -ATM group compared to the base line values after the 12 month prospective measurements subsequent to the $3.6 \%$ increase in CD4+ count at the 6 month interval. In comparison, the CD4+ counts in the + ATM cohort responded similarly to the -ATM group with incremental increases in mean CD4+ count of $6.0 \%$ and $9.5 \%$ at 6 month and 12 month interval respectively.
The differences between the two means in the -ATM and +ATM groups at each CD4+ cell count measure were not significant at $5 \%$ level for Time $0(\mathrm{p}=0.18)$, Time 2 $(p=0.26)$ and Time $3(p=0.09)$.

\section{Effect on VL}

The mean viral loads (VL) for the patients during the study period are recorded in Table 5 .

Table 5: Viral Load (VL) measurements

\begin{tabular}{|c|c|c|c|c|}
\hline & \multicolumn{2}{|c|}{-ATM $(n=267)$} & \multicolumn{2}{|c|}{$+\operatorname{ATM}(n=14)$} \\
\hline & $\begin{array}{l}\text { Mean } \\
\text { Load (SD) }\end{array}$ & $\begin{array}{l}\text { Change from } \\
\text { baseline }\end{array}$ & $\begin{array}{l}\text { Mean Viral } \\
\text { Load (SD) }\end{array}$ & $\begin{array}{l}\text { Change from } \\
\text { baseline }\end{array}$ \\
\hline $\begin{array}{c}\text { Time } 0, \\
6 \text { months } \\
\text { (Retrospective) }\end{array}$ & $\begin{array}{l}21700( \pm 285.0) \\
\text { copies/mL. }\end{array}$ & $+68.8 \%$ & $\begin{array}{l}15825 \quad( \pm 34.7) \\
\text { copies/mL. }\end{array}$ & $+35.5 \%$ \\
\hline $\begin{array}{l}\text { Time 1, } \\
\text { Baseline }\end{array}$ & $\begin{array}{l}12855 \quad( \pm 177.5) \\
\text { copies/mL. }\end{array}$ & $\mathrm{N} / \mathrm{A}$ & $\begin{array}{l}11677 \quad( \pm 51.3) \\
\text { copies/mL. }\end{array}$ & $\mathrm{N} / \mathrm{A}$ \\
\hline $\begin{array}{c}\text { Time } 2, \\
6 \text { months } \\
\text { (Prospective) }\end{array}$ & $\begin{array}{l}8824 \quad( \pm 195.8) \\
\text { copies/mL. }\end{array}$ & $-31.35 \%$ & $\begin{array}{l}9818 \quad( \pm 44.3) \\
\text { copies/mL. }\end{array}$ & $-15.9 \%$ \\
\hline $\begin{array}{c}\text { Time } 3, \\
12 \text { months } \\
\text { (Prospective) }\end{array}$ & $\begin{array}{l}8355 \quad( \pm 331.5) \\
\text { copies/mL. }\end{array}$ & $-35.00 \%$ & $\begin{array}{l}9120 \quad( \pm 36.8) \\
\text { copies/mL. }\end{array}$ & $-21.9 \%$ \\
\hline
\end{tabular}

At baseline, the VL in the -ATM group ranged from undetectable to 79120 copies/mL with an average of 12855 copies $/ \mathrm{mL}$. The +ATM group had a mean VL of 11677 copies $/ \mathrm{mL}$ ranging from undetectable to 25435. The VL in the -ATM group reduced by $31.35 \%$ and $35 \%$ compared to the baseline VL in Time 2 and Time 3 respectively. The differences between the two means in the - ATM and +ATM groups is significant at $5 \%$ level for Time $0(p=0.013)$, marginally significant at Time 1 $(p=0.048)$, Significant at Time $2(p=0.040)$ and not significant at Time $3(\mathrm{p}=0.069)$.

\section{Discussion}

Overall, 65.8\% (185/281) of the patients had used ATM before HIV diagnosis and 77.6\% (218/281) after diagnosis. This indicated a health seeking approach by the respondents through their ATM practitioners after initial HIV diagnosis. These figures are in line with World Health Organization (WHO) estimates of about $80 \%$
Worldwide ATM usage and even closer to a South African estimates of around $70 \% 0^{5,12}$.

A majority of the patients surveyed (95.02\%) did not use ATM concurrently with ARV. With the paucity of data on the concurrent use of ATM and ARV, and the fact that in-vitro studies indicate possible interactions between commonly used ATM and ARV ${ }^{15}$, this finding can be viewed in a positive light. However, 4.98\% (14/281) patients did report the concurrent use of ATM with ARV during the study period. The frequency of concurrent ATM use iscomparable with similar studies in urban centres in Pretoria, South Africa ${ }^{13}$ as well as Kano, Nigeria $^{8}$ which had $4.40 \%$ and $4.3 \%$ incidence rate of concurrent ATM and ARV use respectively. This study differed vastly with a 2004 Uganda study by Langlois-Klassen et $\mathrm{al}^{7}$ which reported a rate of $32.8 \%$ for concurrent ARV

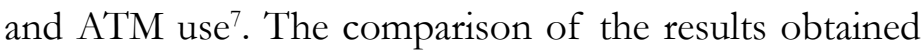
in the current and other similar studies is better compare using Table 6. 
Table 6: Comparison of ATM usage in PLWA

\begin{tabular}{|l|l|l|l|l|l|}
\hline $\begin{array}{c}\text { Clinical trial (CT) } \\
\text { characteristic }\end{array}$ & $\begin{array}{c}\text { eThekwini } \\
\text { Metro, South } \\
\text { Africa } \\
(\mathbf{n = 2 8 1 )}\end{array}$ & $\begin{array}{c}\text { eThekwini } \\
\text { Metro, South } \\
\text { Africa } \\
(\mathbf{n = 2 2 2})^{\mathbf{5}}\end{array}$ & $\begin{array}{c}\text { Pretoria, } \\
\text { South } \\
\text { Africa } \\
(\mathbf{n = 6 7 )}\end{array}$ & $\begin{array}{c}\text { 13 } \\
\text { Kano, } \\
\text { Northwest } \\
\text { Nigeria } \\
(\mathbf{n = 4 3 0 )} \mathbf{8}\end{array}$ & $\begin{array}{c}\text { Kabarole } \\
\text { District, } \\
\text { Western } \\
\text { Uganda } \\
(\mathbf{n = 1 3 7 )}\end{array}$ \\
\hline Period of study & Current study & 2008 & $2004-2005$ & 2014 & 2004 \\
\hline Setting & Urban & Urban & Urban & Urban & Rural \\
\hline $\begin{array}{l}\text { Concurrent ATM } \\
\text { and ARV use }\end{array}$ & $4.98 \%$ & $44.4 \%$ & $4.40 \%$ & $4.30 \%$ & $32.80 \%$ \\
\hline $\begin{array}{l}\text { ATM use after HIV } \\
\text { diagnosis (before } \\
\text { initiation of ARV) }\end{array}$ & $77.60 \%$ & - & - & $20.90 \%$ & $63.50 \%$ \\
\hline $\begin{array}{l}\text { ATM use before } \\
\text { HIV diagnosis }\end{array}$ & $65.80 \%$ & - & - & $27.50 \%$ & $90.40 \%$ \\
\hline
\end{tabular}

The differences between the current study and the Karabole could be attributed to different cultural and socio-economic factors. The current study was done in an urban metro in South Africa and the Karabole study in a rural setting in Western Uganda. The researcher postulates that the lower rate of ATM usage could be due to better access to ART services, as is usually the case in an urban setting, and the fact that the Karabole study was carried out in 2004 before the extensive ART roll-out programmes initiated by most governments.

It is important to note that a 2008 study by Peltzer and Mnqundaniso in the same setting as the current study (urban eThekwini), found an incidence rate of $44.4 \%$ for simultaneous ARV and ATM use ${ }^{5}$. It could be surmised that even greater access to ARV through universal access programs since 2008 and the reduced costs of these treatments would have resulted in a reduced demand for $\mathrm{ATM}^{6}$. Furthermore, there was growing evidence of invitro studies which indicated that commonly used South African ATM interacted with ARV ${ }^{15,16,17}$.

Reduced ATM use in the current study may also be attributed to efforts by health care professionals in communication the potential for herb-drug interactions (HDI) to patients during pre-counselling sessions. This study showed that $91 \%$ of the patients cited a knowledge of these potential HDI and that the health care provider had underscored the potential dangers of simultaneous ARV and ATM use to them during pre-counselling before initi- ation of ART. This is further reiterated by the vast differences in ATM before HIV diagnosis, after HIV diagnosis and after initiation of ARV therapy $(65.8 \%, 77.6 \%$ and $4.98 \%$ respectively).

The majority of the participants were relatively undereducated with only $6.7 \%$ having obtained a tertiary qualification and most (48.4\%) only having a primary education. It was also found that the majority of the patients $(64.4 \%)$ resided in an urban township. This unfortunately mirrors the epidemiology of HIV/AIDS in South Africa which largely affects the uneducated, females and persons of low income ${ }^{4}$. Multivariate analysis, obtained from combining all independent and controlling factors, for predicting ATM use showed that level of education level $(p<0.041)$, place of residence $(p=0.004)$ and age $(p<0.001)$ is associated with concomitant ARV and ATM use.

The ATM used where African potato, Sutherlandia, Stametta and unspecified traditional mixtures (including ubbejani). This showed a similar trend to the 2004, Pretoria study by Malangu which highlighted commonly used ATM as African potato, coconut as well as unspecified crude herbal mixtures ${ }^{7}$.

Concomitant use of ATM is generally discouraged during ARV treatment and so there is a chance of under reporting of the use of ATM use by the participants. This is ex- 
pected in subjective measurements due to the perceived possibility of punitive consequences from the healthcare-provider by the participant if he/she admits to the use of ATM. This could also explain the finding that in all cases, patients who used ATM concurrently with ARV did not communicate their ATM use to their health care provider. This could also further indicate that patients are aware of the potential risks of concomitant use, but however, continue to do so in their attempt to self-medicate.

During the duration of the study, there was a steady increase in CD4+ counts in the cohort taking ARV alone as well as the cohort that used ATM and ARV concomitantly. Similarly, there was on average, a decline in VL in both cohorts, albeit, at different rates. The differences between the two VL means in the -ATM and +ATM groups are less than 0.05 and therefore is significant at $5 \%$ level for Time $0(p=0.013)$, and marginally significant at Time 1 $(p=0.048)$ and significant at Time $2(p=0.040)$. However, the differences in the VL means are not significant at Time $3(p=0.069)$. As a result of the conflicting $p$ values across the time lines, it can be concluded that the effect of ATM on ARV is inconclusive.

Overall, statistical analysis found that in general, the effect of concomitant ARV and ATM use was not clinically significant. This was in concordance with a 2013 study by Gwaza et al study on adult volunteers which showed that hypoxis is not associated with clinically significant changes in the pharmacokinetics of the ARV agent, LPV/r pharmacokinetics ${ }^{18}$.

This study, however, differs from in-vitro studies by Mills et al. in 2005 who demonstrated the potential of hypoxis to increase metabolism of some drugs including ARV due to its significant effects on cytochrome P450 3A4 in-vitro metabolism ${ }^{16}$. Furthermore, a 2014 laboratory study validated the findings of Mills and showed that $H$. bypoxis, E. purpurea, M. oleifera,T. officinale and L. frutescens inhibited major drug metabolising enzymes and had the potential to interact with $A R V^{17}$.

\section{Limitations}

The findings of this study may not be generalisable to PLWA in South Africa due to the fact that the study was concentrated in the eThekwini metro. Several multi-centre studies in various centres (Urban, Per-urban, Rural) could shed more light on the actual prevalence rate of ATM use in PLWA as well as provide more reliable data on the effects of ATM on clinical outcomes of PLWA. Caution is therefore urged in generalising findings to other districts and provinces in the country. Clinical co-variates such as presence of opportunistic infections, changes in weight (BMI) of the patients and occurrence of Adverse Drug Reactions (ADR) as a result of ATM during the study period could not easily be retrieved from patient charts since the data in the patient charts was often disordered or absent. This information could possibly have added value to the study by demonstrating whether or not concomitant use of ATM and ARV may have resulted in increased occurrence of opportunistic infections, deterioration in weight of the participants or increased the incidence of adverse drug reactions in the +ATM cohort.

Additionally, there is a need to explore and understand the knowledge, perceptions and attitudes of the health care workers and quantify their possible role, if any, in the continued reduction of prevalence rates of concurrent ATM and ARV use in PLWA.

The limitations of this study could form the basis of future studies on this subject.

\section{Conclusion}

This study was able to establish the prevalence of ATM use in PLWA as well as other factors which impact on ATM use. This study was also able to show that there were no significant effects on the CD4+ and inconclusive results on the VL of HIV infected patients in the eThekwini Metropolitan area who use ARV and ATM concurrently.

\section{Recommendations}

-The use of population pharmacokinetic approach in order to make the results more generalisable and to better establish a link between ARV plasma levels and concurrent ATM use on various patient characteristics.

-The development of a pharmacodynamic model of the data in order to correlate patient characteristics, ARV plasma levels, ATM plasma levels with CD4+ and VL levels.

- Continued vigilance by health care practitioners in counselling patients to not use ATM and ARV concomitantly. - The full professionalisation of THP and the incorporation of THP in the management of HIV/AIDS. 


\section{Acknowledgements}

This work has only been possible due to the support rendered by Dr Siaka Lougue (statistician) who helped with the data analysis.

\section{Competing interests}

The authors declare that they do not have any commercial interest and did not receive any source of support for the research that may constitute conflict of interest.

\section{References}

1. The Joint United Nations Programme on HIV and AIDS (UNAIDS ) . Fact sheet: 2014 statistics, Geneva, Switzerland, 2014.

2. Shisana O, Rehle T, Simbayi LC, Zuma K, Jooste S, Zungu N, Labadarios D, Onoya D et al. South African National HIV Prevalence, Incidence and Behaviour Survey,2012. Cape Town: HSRC Press. 2014.

3. Richter M. Traditional medicines and traditional healers in South Africa. Discussion paper prepared for the Treatment Action Campaign and AIDS Law Project. 2003. Available online on: http://www.tac.org.za/Documents/ResearchPapers/Traditional_Medicine_briefing. pdf (accessed 18 June 2016).

4. Freeman M, and Motsei M. Planning Healthcare in South Africa - Is there a role for traditional healers? Social Science and Medicine. 1992;34:1183-1190.

5. Mngqundaniso N and Peltzer K. Patients consulting traditional health practitioners in the context of HIV/ AIDS in urban areas in Kwazulu-Natal, South Africa. African Journal of Traditional, Complementary and Alternative Medicines. 2008;5:370-379.

6. Babb DA, Pemba L, Seatlanyane P, Charalambous S, Churchyard GJ, Grant AD. Use of traditional medicine by HIV-infected individuals in South Africa in the era of antiretroviral therapy. Psychol Health Med. 2007;12:314-20. 7. Langlois-Klassen D, Kipp W, Jhangri GS, Rubaale T. Use of traditional herbal medicine by AIDS patients in Kabarole District, western Uganda. Am J Trop Med Hyg. 2007;77:757-763.

8. Tamuno I. Traditional medicine for HIV infected patients in antiretroviral therapy in a tertiary hospital in Kano, Northwest Nigeria. Asian Pacific Journal of Tropical Medicine. 2011;4:152-155.

9. Gyasi RM, Tagoe-Darko E, Mensah CM. Use of Traditional Medicine by HIV/AIDS Patients in Kumasi Metropolis, Ghana: A Cross-sectional Survey. American In- ternational Journal of Contemporary Research. 2013;3:117-129. 10. Mudzviti T, Maponga CC, Khoza S, Ma Q, Morse GD. The Impact of Herbal Drug Use on Adverse Drug Reaction Profiles of Patients on Antiretroviral Therapy in Zimbabwe. AIDS Res Treat. 2012; 434171.

11. G D Hughes, T R Puoane, B L Clark, T L Wondwossen, Q Johnson, W Folk Prevalence andpredictors of Traditional Medicine Use among people living with AIDS (PLWA) on the ARV prophylaxis and treatment in both rural and urban areas in South Africa. Afr J Tradit Complement Altern Med. 2012;9:4:470-84.

12. World Health Organization (WHO). Traditional Medicine Strategy 2014-2023. Geneva: WHO, 2014:15-53.

13. Malangu N. Self-reported use of traditional, complementary and over-the-counter medicines by HIV-infected patients on antiretroviral therapy in Pretoria, South Africa. Afr J Tradit Complement Altern Med. 2007;4:3:273-8.

14. Bloom BS, Retbi A, Dahan S. Evaluation of randomised clinical trials on complementary and alternative medicine. International Journal of technology assessment in bealth care. 2000;16:13-21.

15. Müller AC. and, Kanfer I. Potential pharmacokinetic interactions between antiretrovirals and medicinal plants used as complementary and African traditional medicines. Biopharm. Drug Dispos. 2011;32:458-470.

16. Mills E, Fosterb BC, van Heeswijk R, Phillips E, Wilson K, Leonard B, Kosuge K, Kanfer I. Impact of African herbal medicines on antiretroviral metabolism. AIDS. 2005:19:94-97.

17. Awortwe C, Bouic PJ, Masimirembwa CM and, Rosenkranz B. Inhibition of Major Drug Metabolizing CYPs by Common Herbal Medicines used by HIV/AIDS Patients in Africa- Implications for Herb-Drug Interactions. Drug Metab Lett. 2014;2:83-95.

18. Gwaza L, Aweeka F, Greenblatt R, Lizak P, Huang L, B. Guglielmo J. Co-administration of a commonly used Zimbabwean herbal treatment (African potato) does not alter the pharmacokinetics of lopinavir/ritonavir. Int J Infect Dis. 2013;10:857-61 PubMed

19. World Health Organization (WHO). Antiretroviral therapy for HIV infection in adults and adolescents in resource-limited settings: towards universal access. Recommendations for a public health approach. Geneva. Available online on: http://www.who.int/hiv/pub/ guidelines/adult/en/ (accessed 15 June 2016)

20. Mooore DM, Mermin J, Awor A, Yip B, Hogg RS, Motaner JS. Performance of immunologic responses in 
predicting viral load suppression: implications for monitoring patients in resource-limited settings. $J$ Acquir Immune Defic Syndr 2006;43:436-9.

21. Statistics South Africa (SSA). Ethekwini Municipality. 2013 Available online on: www.statssa.gov.za/?page id=1021\&id=ethekwini-municipality. (accessed on 18 June 2016).
22. KwaZulu-Natal Department of Health. EThekwini health district map 2016. Available online on www.kznhealth.gov.za/ethekwini.htm (accessed on 18 June 2016). 23. Southern African HIV Clinicians Society. Advice Document: Fixed dose combination for accessing antiretroviral therapy. S Afr J HIV Med 2013;14:41-43. 